\title{
MULHERES NA AGRICULTURA FAMILIAR: UMA ANÁLISE NO ESTADO DO PARÁ
}

Helder Epifane Rodrigues

Universidade Federal Rural da Amazônia (UFRA)

Belém - Pará - Brasil

E-mail: helder_erodrigues@yahoo.com.br

ORCID: https://orcid.org/0000-0001-9550-7290

\author{
Mayra Hermínia Simões Hamad Farias do Couto \\ Universidade da Amazônia (Unama) \\ Belém - PA - Brasil \\ E-mail:mayrahamad@gmail.com \\ ORCID: https://orcid.org/0000-0001-9690-8256

\section{Rosa de Nazaré Paes da Silva} \\ Instituto Tecnológico Vale \\ Belém - Pará - Brasil \\ E-mail: rosa.paes@itv.org \\ ORCID: https://orcid.org/0000-0002-3284-1942
}

\section{Marcos Ferreira Brabo}

Instituto de Estudos Costeiros da Universidade Federal do Pará (IECOS-UFPA)

Bragança - Pará - Brasil

E-mail: marcos.brabo@hotmail.com

ORCID: https://orcid.org/0000-0001-8179-9886

\section{Marcos Antônio Souza dos Santos}

Universidade Federal Rural da Amazônia (UFRA)

Belém - PA - Brasil

E-mail: marcos.santos@ufra.edu.br

ORCID: https://orcid.org/0000-0003-1028-1515

Recebido em 18/04/2021. Aprovado em 31/05/2021

DOI: http://dx.doi.org/10.5380/guaju.v7i2.80645

\section{Resumo}

O artigo caracteriza o perfil da mulher na agricultura familiar paraense, com base em dados do Censo Agropecuário de 2017. As análises apresentam as características gerais, produtivas e tecnológicas dos estabelecimentos agropecuários familiares gerenciados por agricultoras, assim como aspectos relacionados ao associativismo, acesso à assistência técnica e crédito rural. No estado do Pará, 57.473 estabelecimentos agropecuários são gerenciados por 
mulheres, o que representa $20 \%$ do total. A maior parcela delas (53\%) possui mais de 45 anos de idade. O nível de escolaridade é baixo e se dedicam, principalmente, ao cultivo de lavouras temporárias, quintais agroflorestais e a criação de pequenos animais, visando a segurança alimentar do grupo familiar e a comercialização de excedentes. Os resultados indicam a necessidade de maior equidade de gênero, pois a "invisibilidade" da mulher e o baixo acesso às políticas públicas, ainda é traço marcante no meio rural. Destacam-se os baixos percentuais de acesso dessas mulheres aos serviços de assistência técnica e extensão rural e aos financiamentos via crédito rural, instrumentos fundamentais para a inovação e sustentabilidade dos sistemas de produção. Conclui-se que as lacunas de gênero continuam a se configurar como um dos principais óbices ao desenvolvimento rural sustentável.

Palavras-chave: Desenvolvimento rural. Equidade de gênero. Mulheres rurais. Amazônia.

\title{
Women in family farming: an analysis in Pará State
}

\begin{abstract}
The article characterizes women profiles in Pará family farming, based on data from the 2017 Agriculture Census. The analyses present the general, productive, and technological characteristics of family farms led by women farmers and aspects related to associations, access to technical assistance, and rural credit. In Parástate, 57,473 agricultural establishments are managed by women, which represent $20 \%$ of the total. Most of them (53\%) are over 45 years of age. The education level is low and they are mainly dedicated to the cultivation of temporary crops, agroforestry yards, and the creation of small animals, aiming at family group food security and surpluses sale. The results indicate the need for greater gender equity, as the "invisibility" of women and the low access to public policies is still a striking feature in rural areas. Low percentages of access by women to technical and extension assistance services and financing via rural credit were stand out. They are fundamental instruments for the innovation and sustainability of production systems. It is concluded that gender gaps continue to be configured as one of the main obstacles to sustainable rural development.

Keywords: Rural development. Gender equity. Rural women. Brazilian Amazon.
\end{abstract}




\section{Introdução}

De acordo com a Lei n 11.326, de 24 de julho de 2006, o conceito de agricultura familiar caracteriza agricultores que detém pequenas propriedades e utilizam-se predominantemente da força de trabalho familiar (BRASIL, 2006). Entretanto, na perspectiva de gênero e considerando a divisão dos trabalhos nos estabelecimentos, ainda que de base familiar, as mulheres têm pouco reconhecimento na condição de produtoras rurais, o que as torna "invisíveis" (BRUMER, 2004).

Gênero, compreende uma construção das diferentes relações socias que as sustentam, considerando fatores culturais, econômicos e ideológicos, que moldam a divisão do trabalho e as relações de poder pautadas por relações hierárquicas (CARVALHO, 2011).

A falta de reconhecimento da mulher como agente econômico dentro das cadeias de valor na agricultura aumenta as desigualdades no campo. Segundo a Organização das Nações Unidas para a Alimentação e Agricultura (FAO, 2011), as lacunas de gênero presentes na sociedade, maiores para as mulheres do que para os homens, acabam por restringir seu acesso aos recursos produtivos, mercados e serviços, afetando a produtividade do setor que, de forma mais ampla, restringe o desenvolvimento econômico e social.

O Fórum Econômico Mundial (2020), no relatório sobre as desigualdades de gênero, divulgou o índice sintético Global Gender Gap Index (GGI), o qual mostra que no período referente ao ano de 2020 o Brasil ocupou apenas a 92a posição entre mais de 153 países pesquisados. Isso evidencia a necessidade de se avançar com estratégias na redução da desigualdade de gênero para alcançar maiores índices de desenvolvimento.

Nesse sentido, a agenda 2030 - assinada em 2015 pelos Estados-membros das Nações Unidas durante a Cúpula sobre o Desenvolvimento Sustentável - possui 17 objetivos e 169 metas e tem como quinto objetivo: "alcançar a igualdade de gênero e o empoderamento das mulheres e meninas". Entre suas ações estão implementar reformas que promovam igualdade de direito, acesso aos recursos econômicos, à propriedade e ao controle da terra, dentre outros tipos de bens e serviços (ONU, 2015), que assim como outras metas são fundamentais, em especial, considerando a realidade da mulher rural.

O fechamento de lacunas submetidas às mulheres, como a ampliação do acesso aos recursos produtivos, representaria um ganho de 20 a 30\% de produtividade, portanto promovendo a redução da pobreza, da fome e trazendo melhoria econômica de forma sustentável (FAO, 2011). Isso teria impacto para os pequenos agricultores, pois, segundo o 
Banco Mundial (2019), os indivíduos que vivem em áreas rurais representam um grande percentual das famílias mais pobres e correspondem a cerca de $79 \%$ das pessoas em situação de extrema pobreza.

No entanto, atuar de forma efetiva na redução de lacunas de gênero na agricultura familiar depende de uma abordagem integrada dos sistemas produtivos e uma vasta compreensão sobre a inserção da mulher na agricultura a partir de dados que possam expressar as realidades regionais. O uso de estatísticas oficiais pode fomentar a elaboração de indicadores com esse objetivo e auxiliar no planejamento e gestão de políticas públicas que visam o desenvolvimento regional. O Instituto Brasileiro de Geografia e Estatística IBGE (2018) publicou um estudo que reforça a importância dos indicadores e destaca dois objetivos principais para esses estudos: enriquecer o debate sobre o tema e colocar na agenda pública a igualdade de gênero como um dos eixos estruturais da formulação de políticas públicas.

À vista disso, o objetivo deste artigo foi caracterizar o perfil da mulher na agricultura familiar a partir de estatísticas oficiais de gênero para o estado do Pará, a fim de obter um perfil das características dessas mulheres, identificar lacunas de gênero e sinalizar para ações que promovam maior equidade e contribuam para o desenvolvimento do meio rural na região.

\section{Metodologia}

A área de referência da pesquisa é o estado do Pará, localizado na região norte do Brasil, composto por 144 municípios que totalizam uma superfície de $1.245 .870,798 \mathrm{~km}^{2}$. A população é estimada em 8,7 milhões de pessoas, sendo que $68 \%$ vivem na área urbana e $32 \%$ (2.389.492) no meio rural. O Índice de Desenvolvimento Humano (IDH) é classificado como médio $(0,646)$, porém, considerando as demais unidades da Federação, ocupa a 24º posição no IDH do país. Essa disparidade também ocorre internamente considerando a divisão regional, com maiores índices na Região Metropolitana de Belém, revelando a grande desigualdade no desenvolvimento das capacidades humanas no Pará como um todo.

Os dados para elaboração do estudo foram obtidos a partir do Censo Agropecuário 2017, publicados pelo Instituto Brasileiro de Geografia e Estatística (IBGE) no SIDRA (Sistema IBGE de Recuperação Automática) e a tabulação e análise foram realizadas com auxílio do programa Microsoft Excel'. 
Adotou-se abordagem quantitativa e descritiva com recorte por sexo, buscando captar características gerais, os aspectos produtivos e tecnológicos, assim como questões referentes ao associativismo, cooperativismo, acesso à assistência técnica e crédito. As variáveis abordadas para caracterização geral da agricultora familiar foram: (a) condição em relação às terras; (b) forma de obtenção da terra; (c) faixa etária; (d) cor ou raça; (e) nível de instrução; (f) área média dos estabelecimentos segundo a condição do produtor familiar; (g) área total dos estabelecimentos; (h) grupos de atividades econômicas desenvolvidas e (i) finalidade da produção familiar. Para os aspectos produtivos e tecnológicos analisou-se: (a) utilização das terras na agricultura familiar; (b) ocupação da mão de obra; (c) tipo de mão de obra ocupada; (d) adoção de práticas agrícolas e (e) uso de insumos na agricultura familiar. Também se avaliou a participação em entidades associativas, acesso aos serviços de assistência técnica, forma de obtenção de informações técnicas e acesso ao crédito rural.

\section{Resultados e discussão}

\subsection{Características gerais}

No Censo Agropecuário 2017 foram identificados 5.073.324 estabelecimentos agropecuários no país. Deste total, 19\% são gerenciados por mulheres; valor superior ao observado no Censo Agropecuário de 2006, cujo percentual foi de 13\% (IBGE, 2017). No estado do Pará houve considerável aumento desse percentual que, em 2006, era de $11 \%$ e, em 2017, atingiu 20\% e envolve um total de 57.473 estabelecimentos (IBGE, 2017).

Considerando as diferentes mesorregiões do Pará, o maior percentual foi observado na Região Metropolitana de Belém (29,47\%). Isto se deve, principalmente, ao maior protagonismo da mulher em sistemas de produção da agricultura urbana e periurbana que são muito presentes em todos os municípios dessa região (SANTOS; SILVA, 2007; SILVA et al., 2019). No Sul do Pará, composto pelas mesorregiões do Sudeste e Sudoeste Paraense, se observam os percentuais mais baixos, em torno de $17 \%$. Nestas regiões predominam a pecuária de corte e também a agricultura de grãos, além da agricultura familiar muito presentes em assentamentos de reforma agrária. Nas mesorregiões do Baixo Amazonas, Marajó e Nordeste Paraense os percentuais ficaram muito próximos à média estadual de $20 \%$. São regiões com forte participação da agricultura familiar e também do extrativismo vegetal e produtos da sociobiodiversidade. 
Segundo a FAO (2011), para as mulheres, ainda que responsáveis pelos estabelecimentos, o direito de uso da terra que pode incluir algum poder de decisão sobre o processo de produção e uso do recurso, não necessariamente representa o aproveitamento de todos benefícios possíveis derivados do seu uso. Neste sentido, a menor participação das mulheres reforça a subordinação delas aos homens, o que segundo Spanevello, Matte e Boscardin (2016), é uma realidade recorrente, uma vez que as mulheres quase sempre ocupam papeis secundários dentro dos estabelecimentos.

Tabela 1 - Condição do agricultor familiar em relação às terras, por sexo do responsável do estabelecimento, estado do Pará

\begin{tabular}{ccc}
\hline Condição em relação às terras & Homens (\%) & Mulheres (\%) \\
\hline Próprias & 86,11 & 85,89 \\
Concedidas por órgão fundiário ainda sem titulação definitiva & 4,90 & 4,86 \\
Arrendadas & 0,74 & 0,54 \\
Em parceria & 2,19 & 2,43 \\
Em regime de comodato & 2,50 & 2,68 \\
Ocupadas & 3,56 & 3,60 \\
\hline Total & 100,00 & 100,00 \\
\hline
\end{tabular}

Fonte: Censo Agropecuário, 2017.

Considerando o fator condição em relação a terra, a quase totalidade do percentual de agricultores encontram-se na condição de proprietários, 86,11\% de homens e 85,89\% de mulheres (Tabela 1). Em uma relação ponderada no número de homens e mulheres, observa-se que elas representam apenas 21,1\% (43.878) em relação ao total de proprietários homens. Esse resultado, em parte proporcional ao menor número de mulheres responsáveis pelos estabelecimentos, se configura como uma decorrência da tradicional relação de estereótipos de gênero que é delegada a elas no acesso à terra.

Outro aspecto fundamental para compreender o cenário de desigualdade no acesso à terra é a forma pelas quais são obtidas, o que para as mulheres ocorre, principalmente, por meio de herança ou doação em 45,52\% dos casos. Em contrapartida, 46,68\% dos homens adquirem as terras principalmente por compra, como observado na Tabela 2. Esses dados corroboram com os estudos empíricos de Deere e Léon (2003), nos quais as mulheres tenderiam a adquirir terras tornando-se proprietárias por herança, enquanto que o mercado fundiário corresponderia ao meio de aquisição de terras mais predominante para os homens. 
Porém, é necessário ter cautela ao interpretar esse resultado, pois na maioria das vezes são os filhos homens que têm a prioridade de herança das terras, e não as filhas, a não ser que seus maridos sejam agricultores (BRUMER, 2004).

Tabela 2 - Forma de obtenção da terra pelo agricultor familiar, por sexo do responsável do estabelecimento, estado do Pará

\begin{tabular}{ccc}
\hline Forma de obtenção & Homens (\%) & Mulheres (\%) \\
\hline Compra de particular & 46,68 & 38,65 \\
Herança ou doação & 37,70 & 45,52 \\
Posse não titulada & 5,42 & 5,41 \\
Titulação ou licença de ocupação por reforma agrária & 4,96 & 4,65 \\
Concessão de direito real de uso & 1,66 & 1,90 \\
Usucapião & 1,06 & 0,96 \\
Não sabe & 0,87 & 1,04 \\
Titulação de comunidade quilombola & 0,78 & 0,99 \\
Concessão de terra indígena & 0,47 & 0,47 \\
Titulação por regulamentação na Amazônia legal (Programa Terra Legal) & 0,24 & 0,29 \\
Compra via crédito fundiário & 0,15 & 0,11 \\
\hline Total & 100,00 & 100,00 \\
\hline
\end{tabular}

Fonte: Censo Agropecuário, 2017.

Em conjunto com essas informações, Butto e Hora (2008) apontam que no código civil e nos direitos constituintes referentes aos sistemas de herança, é condicionado a mulher o direito à terra mediante sua condição civil e a sua posição na família. As autoras afirmam, também, que o acesso à propriedade por parte das mulheres é escasso, apresentando grande implicação quando se considera as relações de gênero, o que sinaliza para a necessidade de mudanças profundas nas políticas. Segundo Doss e Meinzen-dick (2020), o direito de acesso e posse tem ganhado cada vez mais importância como meio de promoção da igualdade de gênero com efeitos no desenvolvimento econômico e na redução da pobreza, também relacionando esse direito a um apanhado de outras características da mulher, como renda, educação, idade, além de características coletivas no âmbito social, cultural e características físicas e geografias da própria terra.

As disparidades também foram observadas quando considerada a área média dos estabelecimentos (hectares), em que dada a mesma condição em relação aos estabelecimentos, observa-se que há um percentual maior de mulheres em unidades de 
área menores quando comparadas aos homens, com a média total da área de 25,6 ha para as mulheres e 38,8 ha para os homens, como consta na Tabela 3. Esses são resultados expressivos que, em última análise, demonstram a desigualdade de gênero no acesso à terra no Pará, o que também exerce influência nos menores resultados de rentabilidades e produtividades quando observada sua participação na produção agrícola, visto que o acesso à terra é um dos principais fatores de produção.

Tabela 3 - Área média dos estabelecimentos (hectares) segundo a condição do produtor familiar, por sexo do responsável do estabelecimento, estado do Pará

\begin{tabular}{ccc}
\hline Condição do produtor & Homens & Mulheres \\
\hline Proprietário(a) & 40,62 & 26,84 \\
Concessionário(a) ou assentado(a) aguardando titulação definitiva & 45,83 & 33,66 \\
Arrendatário(a) & 25,20 & 13,17 \\
Parceiro(a) & 14,19 & 9,76 \\
Comandatário(a) & 12,98 & 6,53 \\
Ocupante & 27,40 & 14,65 \\
\hline Total & 38,76 & 25,62 \\
\hline
\end{tabular}

Fonte: Censo Agropecuário 2017.

No estado do Pará, grande parte dos estabelecimentos da agricultura familiar têm áreas inferiores a dois hectares. A proporção de mulheres que gerenciam estes estabelecimentos de menor tamanho é de 30,35\%, enquanto que a proporção de homens é de 20,20\%. Também é observado um percentual expressivo de mulheres nos estabelecimentos entre 20 e 50 ha (20,21\%), mas, de modo geral, a tendência é de que à medida que se amplia o tamanho das propriedades o percentual de homens passe a ser superior e o de mulheres inferior (Tabela 4).

Na publicação da FAO (2012) intitulada Manual sobre gênero na agricultura, ao analisar parâmetros sobre o direito e uso da terra, o sexo configura-se como um dos fatores determinantes no acesso à terra e as mulheres quase sempre são destinadas a lotes menores que os dos homens. 
Tabela 4 - Área total dos estabelecimentos da agricultura familiar, por sexo do responsável do estabelecimento, estado do Pará

\begin{tabular}{ccc}
\hline Grupos de área total (ha) & Homens (\%) & Mulheres (\%) \\
\hline Menos de 2 & 20,20 & 30,35 \\
De 2 a menos de 5 & 11,58 & 13,88 \\
De 5 a menos de 10 & 8,42 & 8,77 \\
De 10 a menos de 20 & 9,41 & 9,02 \\
De 20 a menos de 50 & 23,20 & 20,21 \\
De 50 a menos de 100 & 14,41 & 10,21 \\
De 100 ha e mais & 11,17 & 6,10 \\
Produtor sem área & 1,62 & 1,45 \\
\hline Total & 100,00 & 100,00 \\
\hline
\end{tabular}

Fonte: Censo Agropecuário, 2017.

Quando consideradas as atividades econômicas desenvolvidas pelos agricultores familiares, os resultados na Tabela 5 mostram que as mulheres dedicam-se, sobretudo, às atividades que compreendem lavouras temporárias $(37,4 \%)$ que, em geral, são diversificadas, visto que na agricultura familiar existe uma grande variação produtiva, com mão de obra predominantemente familiar, conforme diretrizes da Lei n. 11.326, de 24 de julho de 2006 (BRASIL, 2006).

A diversificação da produção ajuda a garantir a renda e a subsistência dos pequenos produtores e as mulheres, nesse contexto, desempenham papel essencial na melhoria da produtividade agrícola, segurança alimentar e nutricional, podendo contribuir, portanto, na promoção de maior desenvolvimento para as famílias rurais. Segundo a ONU (2015), na agenda 2030 para o desenvolvimento sustentável uma das metas é dobrar a produtividade agrícola e a renda dos pequenos produtores de alimentos, especificamente das mulheres, agricultores familiares, povos indígenas, entre outros. Tal iniciativa surge como um meio de combater a fome e a pobreza no planeta. Normalmente esses pequenos agricultores produzem culturas de base alimentar, a exemplo da mandioca que no estado do Pará tem grande expressividade e contribui substancialmente para a segurança alimentar das famílias paraenses.

Observa-se que 29,15\% das mulheres se dedicam à pecuária e criação de animais e um percentual de 14,99\% delas vivem do extrativismo e da exploração de produtos florestais. A participação em relação ao sexo está ligeiramente próxima em quase todos os grupos de atividades, apontando a importância da mulher como produtora nos diferentes processos de várias cadeias produtivas, estando em apenas alguns casos inferior à participação dos 
homens. Contudo, os resultados são coerentes considerando que tradicionalmente as mulheres exercem atividades como a coleta de sementes e o cuidado com animais. De acordo com Tara Satyavathi, Bharadwaj e Brahmanand (2010), apesar de desempenharem papéis imprescindíveis em todas as esferas da atividade agrícola, as mulheres participam menos em trabalhos de maior exigência física.

Considerando de maneira mais crítica a divisão do trabalho na agricultura familiar, estudos empíricos mostram que, apesar de toda a família estar envolvida nas atividades, ao analisar o papel da mulher é observado que normalmente elas são excluídas ou "poupadas" de atividades consideradas principais, sendo direcionadas a afazeres domésticos, podendo também exercer papel auxiliar nas atividades produtivas. O ponto determinante na ampliação da desigualdade ocorre por sua atividade não ser tratada como trabalho e quase sempre não possuir remuneração, tornando-as mais vulneráveis (BRUMER; ANJOS, 2008; SILIPRANDI, 2012; SPANEVELLO; MATTE; BOSCARDIN, 2016) e deixando-as de fora de estágios críticos como a tomada de decisões produtivas e uso de recursos (SUNDERLAND et al., 2014).

Tabela 5 - Grupos de atividades econômicas desenvolvidas pelos agricultores familiares, por sexo do responsável do estabelecimento, estado do Pará

\begin{tabular}{ccc}
\hline Grupos de atividades & Homens (\%) & Mulheres (\%) \\
\hline Produção de lavouras temporárias & 35,57 & 37,4 \\
Pecuária e criação de outros animais & 29,01 & 29,15 \\
Produção de lavouras permanentes & 16,62 & 15,59 \\
Produção florestal - florestas nativas & 15,94 & 14,99 \\
Horticultura e floricultura & 1,38 & 1,36 \\
Pesca & 0,98 & 1,01 \\
Produção florestal - florestas plantadas & 0,23 & 0,23 \\
Aquicultura & 0,17 & 0,18 \\
Produção de sementes e mudas certificadas & 0,09 & 0,09 \\
\hline Total & 100,00 & 100,00 \\
\hline
\end{tabular}

Fonte: Censo Agropecuário, 2017.

Quanto à finalidade da produção para famílias de agricultores familiares, geralmente existe um contingente importante da produção voltada ao autoconsumo, o que está fortemente associado às características socioeconômicas e à necessidade de subsistência familiar. Segundo o Ministério da Agricultura, Pecuária e Abastecimento - MAPA (2019), é característico da agricultura familiar uma produção diversificada com parte destinada para a subsistência e outra destinada ao mercado. Neste contexto, há um destaque para 
a importância da mulher na melhoria da qualidade de vida da família. Segundo Masamha, Uzokwe e Thebe (2018), à medida que se aumenta a igualdade de gênero, com a maior participação da mulher, aumentam também a segurança alimentar, a sustentabilidade do sistema e promove-se a redução da pobreza no agregado familiar.

Essa relevância para o sustento da família pode ser observada na Tabela 6, em que se constata um maior percentual da produção feminina (34,85\%) voltada para a subsistência familiar. Esse resultado sinaliza para uma maior preocupação da mulher com a garantia da segurança alimentar, assim como ser resultante de efeitos intrínsecos à sua vulnerabilidade na condição de maior desigualdade quanto à comercialização da produção, cujo percentual é de $65,15 \%$ para as mulheres, enquanto para os homens esse percentual é de $73,11 \%$. 0 baixo acesso aos recursos produtivos ampliam lacunas, resultando também em menores rendimentos e, consequentemente, menor excedente comercializável.

Tabela 6 - Finalidade da produção familiar (\%), por sexo do responsável do estabelecimento, estado do Pará

\begin{tabular}{cccc}
\hline Finalidade da produção & Homens (\%) & Mulheres (\%) & Total (\%) \\
\hline $\begin{array}{c}\text { Consumo próprio e de pessoas com laços de } \\
\text { parentescos com o produtor }\end{array}$ & 26,89 & 34,85 & 28,58 \\
Comercialização da produção & 73,11 & 65,15 & 71,42 \\
\hline Total & 100,00 & 100,00 & 100,00 \\
\hline
\end{tabular}

Fonte: Censo Agropecuário, 2017.

$\mathrm{Na}$ análise do perfil das agricultoras, levando em consideração a idade, percebese uma relativa predominância de mulheres com mais de 35 anos, representando 22,51\%, seguida da faixa etária de mais de 45 anos com percentual de 21,24\%. Em relação aos homens, o percentual de agricultores na faixa de idade superior a 45 anos é ainda maior, com $24,49 \%$. Existe um percentual pequeno de homens e mulheres mais jovens em idades inferiores a 25 anos, com 3,22\% e 5,49\% respectivamente, o que pode ser observado na Tabela 7. Portanto se evidencia um contingente maior de pessoas mais velhas, fenômeno esse que segundo Boessio e Doula (2016), resulta do êxodo rural, principalmente por parte dos jovens, com tendência ao envelhecimento e a "masculinização" do campo. 
Tabela 7 - Faixa etária dos agricultores familiares, por sexo do responsável do estabelecimento, estado do Pará

\begin{tabular}{ccc}
\hline Faixa etária & Homens (\%) & Mulheres (\%) \\
\hline Menor de 25 anos & 3,22 & 5,49 \\
De 25 a menos de 35 anos & 13,52 & 18,28 \\
De 35 a menos de 45 anos & 23,00 & 22,51 \\
De 45 a menos de 55 anos & 24,49 & 21,24 \\
De 55 a menos de 65 anos & 19,77 & 17,82 \\
De 65 a menos de 75 anos & 11,56 & 10,34 \\
De 75 anos e mais & 4,43 & 4,32 \\
\hline Total & 100,00 & 100,00 \\
\hline
\end{tabular}

Fonte: Censo Agropecuário, 2017.

Além do perfil etário, composto relativamente de mulheres mais velhas, existe o levantamento dos perfis referentes aos extratos que compreendem a cor ou raça do agricultor familiar, um indicador importante considerando as desigualdades étnico-raciais. De acordo com o IBGE (2019), as populações de cor ou raça preta ou parda encontram-se em severas desvantagens em relação à branca em dimensões como: mercado de trabalho, distribuição de rendimento, condições de moradia, educação, violência, representação política, além de estarem em maior proporção abaixo da linha de pobreza, terem piores condições de moradia e menos acesso a bens e serviços. Nesse sentido, os resultados apontaram que quase $70 \%$ dos agricultores se declaram de cor parda, 11,05\% se declara preta, 17\% branca e menos de $1 \%$ se declara amarela ou indígena (Tabela 8).

Tabela 8 - Cor ou raça do agricultor familiar, por sexo do responsável do estabelecimento, estado do Pará

\begin{tabular}{ccc}
\hline Cor ou raça & Homens (\%) & Mulheres (\%) \\
\hline Parda & 69,67 & 69,49 \\
Branca & 17,72 & 17,41 \\
Preta & 11,05 & 11,34 \\
Indígena & 0,91 & 0,99 \\
Amarela & 0,66 & 0,77 \\
\hline Total & 100,00 & 100,00 \\
\hline
\end{tabular}

Fonte: Censo Agropecuário, 2017. 
Considerando o nível de instrução dos agricultores familiares (Tabela 9), observou-se a baixa escolaridade da grande maioria dos produtores. Nota-se um percentual preocupante de homens e mulheres que nunca frequentaram a escola, 18,11\% e 15,64 \% respectivamente, e um contingente maior de produtores com o nível médio, sendo 34,09\% para os homens e $35,36 \%$ para as mulheres.

Esse contexto impacta fortemente no acesso ao conhecimento e às inovações tecnológicas, principalmente no âmbito da agricultura familiar em que o ambiente é cada vez mais dinâmico, complexo e incerto (PETRY et al., 2019). A inovação promove a redução de custos e aumento de produção com o uso mais eficiente e racional de insumos e com o emprego maior de novas práticas e/ou tecnologias (VIEIRA FILHO, 2017; COROMALDI; PALLANTE; SAVASTANO, 2015), o que gera efeitos na qualidade de vida dessas famílias e é imprescindível na garantia da dignidade humana.

Há um percentual maior de mulheres com nível superior em relação aos homens, ainda que pequeno, cerca de $3 \%$ do total, representa uma tendência no país segundo o Instituto Nacional de Estudos e Pesquisas Educacionais Anísio Teixeira - INEP (2018). Dados do Censo da Educação Superior de 2016 mostram que as mulheres já correspondem à maioria na educação superior brasileira. No âmbito rural, autores apontam para uma tendência maior da inserção das mulheres nas ciências agrárias (NOBRE, 2012; BARROS; MOURÃO, 2018) e a maior capacitação e maiores níveis de educação por parte das mulheres contribui direta e indiretamente para a redução da desigualdade de gênero no meio rural. 
Tabela 9 - Nível de instrução do agricultor familiar, por sexo do responsável do estabelecimento, estado do Pará

\begin{tabular}{ccc}
\hline Nível de instrução & Homens (\%) & Mulheres (\%) \\
\hline Regular do ensino fundamental ou $1^{\circ}$ grau & 34,09 & 35,36 \\
Nunca frequentou escola & 18,11 & 15,64 \\
Antigo primário (elementar) & 15,64 & 13,08 \\
Classe de alfabetização - CA & 15,41 & 12,35 \\
Regular de ensino médio ou $2^{\circ}$ grau & 8,75 & 13,52 \\
$\quad$ Antigo ginasial (médio $1^{\circ}$ ciclo) & 3,2 & 3,17 \\
Alfabetização de jovens e adultos - AJA & 1,96 & 1,71 \\
$\quad$ Nível superior & 1,27 & 3,02 \\
EJA - Educação de jovens e adultos e supletivo do & 0,67 & 0,79 \\
ensino fundamental ou do $1^{\circ}$ grau & 0,60 & 0,85 \\
Técnico de ensino médio ou do $2^{\circ}$ grau & 0,18 & 0,24 \\
Antigo científico, clássico, etc. (médio $2^{\circ}$ ciclo) & 0,13 & 0,27 \\
EJA - Educação de jovens e adultos e supletivo do \\
ensino médio ou do $2^{\circ}$ grau & 100,00 & 100,00 \\
\hline Total & & \\
\hline
\end{tabular}

Fonte: Censo Agropecuário 2017.

Esses parâmetros de caracterização são imprescindíveis na análise da realidade dessas agricultoras e apresentam efeitos inter-relacionados a todos os aspectos subsequentes que configuram a relação sistêmica entre o produtor e os sistemas produtivos. É essencial a compreensão das relações de desigualdade e as lacunas presentes, em particular, quando considerados os atores mais vulneráveis e que estão presentes em todas as etapas do processo produtivo.

\subsection{Aspectos produtivos}

Considerando os aspectos produtivos no contexto da agricultura familiar a partir das informações estruturais do setor, observa-se que no estado do Pará, em maior parte, o uso das terras pelos agricultores é destinado às áreas de pastagens e os valores percentuais para homens e mulheres são de $41,75 \%$ e 36,83\%, respectivamente (Tabela 10). Conforme dados do Boletim Agropecuário do Pará (2017) e da Fundação Amazônia de Amparo a Estudos e Pesquisas do Pará - FAPESPA (2017), as regiões Sudeste e Sudoeste paraense assumem o protagonismo nessa atividade. 
É perceptível o grande percentual de áreas não utilizadas que correspondem à mata ou florestas naturais para preservação e reserva legal:o percentual de homens que detém esse tipo de área é de 23,65\% e o de mulheres, 25,27\%; assim como áreas preservadas de matas e/ou florestas naturais com percentuais de 11,06\% para homens e 10,86\% para mulheres. Em parte, o percentual observado relaciona-se aos efeitos positivos do código florestal brasileiro, contudo, para Santos e Mitja (2012) a agricultura familiar pode configurar-se como alternativa modeladora de desenvolvimento mais inclusivo e ambientalmente equilibrado. Configura-se como a alternativa mais sustentável em uma agricultura diversificada com menos externalidades negativas, comparativamente ao modelo hegemônico da agricultura patronal, que segundo Dal Soglio e Kubo (2016), baseia-se na dependência cada vez maior de fertilizantes e agrotóxicos na monocultura.

Tabela 10 - Utilização das terras na agricultura familiar (\%), por sexo do responsável do estabelecimento, estado do Pará

\begin{tabular}{ccc}
\hline Utilização das terras & Homens (\%) & Mulheres (\%) \\
\hline Pastagens plantadas & 41,75 & 36,83 \\
Matas ou florestas naturais destinadas à preservação & 23,65 & 25,27 \\
permanente ou reserva legal & 11,06 & 10,86 \\
Matas e/ou florestas naturais & 5,75 & 4,91 \\
Pastagens naturais & 4,30 & 4,98 \\
Lavouras permanentes & 3,82 & 4,64 \\
Lavouras temporárias & 2,94 & 4,56 \\
Sistemas agroflorestais & 0,15 & 0,25 \\
Matas ou florestas plantadas & 0,04 & 0,04 \\
Flores e plantas ornamentais & 6,54 & 7,66 \\
\hline Outros usos* & 100,00 & 100,00 \\
\hline Total &
\end{tabular}

Fonte: Censo Agropecuário, 2017.

Nota: $\left(^{*}\right)$ Inclui área de lâmina d'água, tanques, lagos, açudes, área de águas públicas para aquicultura, de construções, benfeitorias ou caminhos, de terras degradadas e de terras inaproveitáveis.

Noestado do Pará, a ocupação da mão de obra feminina estáalocada, principalmente, na produção em lavouras temporárias (38,67\%), seguida da produção florestal $(16,24 \%)$ e lavouras permanentes $(15,11 \%)$, conforme a Tabela 11, demonstrando o importante papel das mulheres na produção destas lavouras e de tudo que é produzido pela agricultura familiar no estado. Entretanto, elas recebem menor remuneração segundo o Programa das Nações Unidas para o Desenvolvimento - PNUD (2017). Considerando a renda média do trabalho em 2010, a mulher apresentou renda $28 \%$ inferior à renda média do trabalho dos homens, 
suscitando a elaboração de trabalhos mais aprofundados que considerem os determinantes e as conjunturas das relações de trabalho para as mulheres rurais.

Tabela 11 - Ocupação da mão de obra (\%) na agricultura familiar (\%), por sexo do responsável do estabelecimento, estado do Pará

\begin{tabular}{ccc}
\hline Grupo de atividade & Homens (\%) & Mulheres (\%) \\
\hline Produção de lavouras temporárias & 36,40 & 38,67 \\
Pecuária e criação de outros animais & 27,54 & 27,20 \\
Produção de lavouras permanentes & 16,80 & 15,11 \\
Produção florestal - florestas nativas & 16,64 & 16,24 \\
Horticultura e floricultura & 1,24 & 1,23 \\
Pesca & 0,89 & 1,05 \\
Produção florestal - florestas plantadas & 0,23 & 0,23 \\
Aquicultura & 0,18 & 0,17 \\
Produção de sementes e mudas certificadas & 0,07 & 0,09 \\
\hline Total & 100,00 & 100,00 \\
\hline
\end{tabular}

Fonte: Censo Agropecuário. 2017.

Tomando como base o tipo de mão de obra ocupada para visibilizar os dados que evidenciam a desigualdades na divisão do trabalho no âmbito da mulher, é feita a desagregação sobre pessoal ocupado com e sem laços de parentesco com o produtor. Conforme Nobre (2012), o objetivo, ainda que de forma aproximada, é trazer maior visibilidade ao trabalho desempenhado pelas agricultoras.

Deste modo, nota-se que o percentual da mão de obra ocupada com laços de parentesco com o produtor é de 82,74 \% nos estabelecimentos gerenciados por homens, e 87,33 \% para as mulheres (Tabela 12). Essa é uma perspectiva importante no parâmetro das relações de gênero envolvendo poder e hierarquia na propriedade, pois as reconhece como produtivas em suas diversas tarefas exercidas nos estabelecimentos rurais, que em sua maioria são chefiados por homens. Esse resultado conforme Brasier et al., (2014), configura um possível cenário no qual as mulheres podem estar se identificando mais como agricultoras e tendo maior aceitação por partes da sociedade, considerando cada vez mais a importância do seu trabalho. 
Tabela 12 - Tipo de mão de obra ocupada (\%) na agricultura familiar, por sexo do responsável do estabelecimento, estado do Pará

\begin{tabular}{ccc} 
Tipo de mão de obra ocupada & Homem (\%) & Mulher (\%) \\
\hline $\begin{array}{ccc}\text { Produtor e pessoas com laços de parentesco com o produtor } \\
\text { Trabalhadores sem laços de parentesco com o produtor }\end{array}$ & 82,72 & 87,33 \\
\hline Total & 17,28 & 12,67 \\
\hline
\end{tabular}

Fonte: Censo Agropecuário, 2017.

O entendimento da divisão social do trabalho na alocação da mão de obra feminina, importante no desenvolvimento de políticas públicas voltadas para a mulher agricultora familiar, compreende um dos grandes desafios contidos em dados censitários nos resultados que incorporam dimensões de variáveis latentes. A recomendação do Programa das Nações Unidas para o Desenvolvimento - PNUD (2017), de reduzir as desigualdades e promover maiores índices desenvolvimento, consiste justamente em produzir e analisar dados de maneira detalhada e desagregada, levando em consideração as particularidades de diferentes grupos.

\subsection{Aspectos tecnológicos}

Quanto à adoção de práticas agrícolas no âmbito da agricultura familiar (Tabela 13), nota-se um percentual expressivo de agricultores homens e mulheres que não fazem o uso racional dos recursos, correspondendo a $44,6 \%$ dos agricultores e $45,31 \%$ de agricultoras que não adotam nenhum tipo prática agrícola. Na agricultura familiar percebe-se relutância de quase $50 \%$ na adoção de novas formas de manejo produtivo além da tradicionalmente empregada. Segundo Fortini, Braga e Freitas (2020), isso se deve ao fato de que, para alguns produtores, novas práticas produtivas são vistas com incerteza e receio em razão de possíveis perdas de lucratividade, produtividade e acompanhadas de aumento de custo.

Entre as práticas de manejo e conservação mais utilizadas pelas mulheres estão: o manejo florestal com 11,51\%, pousio ou descanso de solos com 10,58\% e a rotação de culturas com 7,77\%. Para Muller et al. (2001), a adoção dessas práticas de conservação deve ser implantada desde o início como forma de manter o potencial produtivo do solo.

Em todos os tipos de práticas observadas, não há variação significativa que aponte de forma efetiva para uma predisposição maior de ambas as partes na adoção destas práticas agrícolas. Segundo o Instituto de Pesquisa Econômica Aplicada - Ipea (2017), a 
baixa escolaridade e qualificação das famílias pode representar um dos motivos da falta de utilização e adoção de tecnologias. Os baixos níveis de adoção de tratos culturais e o uso de práticas incorretas no sistema produtivo resultam em perdas de produção e baixos níveis de rendimento nos estabelecimentos rurais. Essas práticas conforme Confederação Nacional de Municípios - CNM, compreendem inovações importantes na ampliação da produtividade e do uso sustentável do recurso, combate à fome e a desigualdade, sendo necessário maior incentivo à produção agrícola sustentável junto a esses pequenos produtores (CNM, 2016).

Tabela 13 - Adoção de práticas agrícolas (\%) na agricultura familiar, por sexo do responsável do estabelecimento, estado do Pará

\begin{tabular}{ccc}
\hline Tipos de práticas agrícolas & Homens (\%) & Mulheres (\%) \\
\hline Manejo florestal & 11,45 & 11,51 \\
Pousio ou descanso de solos & 10,27 & 10,58 \\
Rotação de culturas & 8,49 & 7,77 \\
Plantio em nível & 2,01 & 1,77 \\
Proteção e/ou conservação de encostas & 1,44 & 1,19 \\
Uso de agricultura orgânica & 1,18 & 1,25 \\
Recuperação de mata ciliar & 0,98 & 0,67 \\
Reflorestamento para proteção de nascentes & 0,72 & 0,55 \\
Uso de pecuária orgânica & 0,5 & 1,51 \\
Estabilização de voçorocas & 0,27 & 0,32 \\
Outra & 30,48 & 30,59 \\
Nenhuma & 44,6 & 45,31 \\
\hline
\end{tabular}

Fonte: Censo Agropecuário, 2017.

Em relação ao uso de insumos "modernos" na agricultura familiar (Tabela 14), observa-se que mais de $80 \%$ dos agricultores não utilizam adubação química e orgânica, assim como calcário e outros corretivos do solo. Nos estabelecimentos em que as mulheres são responsáveis, o percentual corresponde a $84,07 \%$, em contraponto a $80,19 \%$ nos estabelecimentos dos homens. Esses resultados apontam para profunda restrição de acesso a insumos pela agricultura familiar, principalmente considerando as mulheres. Segundo relatório do Banco mundial (2011), as agricultoras tradicionalmente têm menos acesso a insumos, serviços, infraestrutura e tecnologias de produção quando comparadas aos homens e afirma que as diferenças de produção, existentes em função dessas lacunas de gênero, desaparecem quando o acesso aos insumos é levado em consideração. 
É observada uma propensão maior das mulheres na utilização de adubos orgânicos se comparado ao percentual dos homens, sendo 7,15\% para as agricultoras e 6,17\% para agricultores, uma variação de cerca de 1 ponto percentual. Os estabelecimentos gerenciados por homens apresentam taxas percentuais maiores no uso de agrotóxicos e adubação química, comprovando uma maior predisposição das agricultoras paraenses na transição de modelos de produção convencional para modelos de agricultura mais sustentável.

Tabela 14 - Uso de insumos (\%) na agricultura familiar, por sexo do responsável do estabelecimento, estado do Pará

\begin{tabular}{ccc}
\hline Uso de insumo & Homens (\%) & Mulheres (\%) \\
\hline Não fez adubação & 80,19 & 84,07 \\
Uso de agrotóxicos & 15,41 & 10,20 \\
Adubação química & 7,82 & 5,07 \\
Adubação orgânica & 6,17 & 7,15 \\
Adubação química e orgânica & 4,95 & 3,10 \\
Calcário e outros corretivos & 4,39 & 2,75 \\
\hline
\end{tabular}

Fonte: Censo Agropecuário, 2017.

A tendência da participação da mulher na agricultura orgânica mundial é crescente, com impactos importantes sobre seu empoderamento, visto que elas variam suas atividades tanto na produção vegetal como animal, desempenhando papéis multidimensionais. Isso permite que elas apliquem seus conhecimentos tradicionais, diversifiquem sua renda, reduzam riscos financeiros e custos com insumos (NATH; ATHINUWAT, 2020).

\subsection{Associativismo, cooperativismo, assistência técnica e crédito rural}

A Tabela 15 ilustra a participação das agricultoras em entidades associativas e mostra que, no Pará, as principais formas de organização social são as entidades de classe e sindicatos, cujo percentual de mulheres associadas é de 33,25\%; seguida de Associação/ movimento de produtores com 9,56\%. Conforme Almeida (2010), o estado é marcado por movimentos e pela luta sindical, com forte presença da Igreja Católica a partir das Comunidades Eclesiais de Base (CEB) na formação do Sindicato dos Trabalhadores Rurais - STR, associações e cooperativas, especialmente na região que compreende o Baixo Tocantins. De modo comparativo, não houve grande variação nos percentuais de vínculo 
às entidades associativas em relação a participação de homens e mulheres, que, em sua maioria, apresentaram percentuais relativamente baixos.

No contexto estadual, esses parâmetros são importantes e expressam o nível de organização social que essas agricultoras apresentam. Segundo relatório do Programa das Nações Unidas para o Desenvolvimento (2016), as instituições sociais organizadas - como cooperativas, comunidade, clubes sociais dentre outros - promovem maiores índices de desenvolvimento humano ao ampliar liberdades individuais, especialmente entre as pessoas mais marginalizadas, com o efeito de potencializar as capacidades coletivas.

Dessa forma, a organização social das mulheres em cooperativas e outros sistemas de participação cívica são essenciais para formação de uma sociedade com maior igualdade de gênero e maior desenvolvimento econômico, social e ambiental. Estas entidades podem trabalhar em comunidades locais como ferramentas catalizadoras de resultados por meio de trabalho conjunto e de metas comuns por parte dos agricultores, sendo, segundo Putnam (2002), essencial reforçar normas e valores da comunidade cívica e fortalecer hábitos de cooperação, solidariedade e espírito público, visto que favorecem a formação de sociedades mais democráticas.

Logo, em uma sociedade mais participativa e organizada, como efeito, existe maior alcance das políticas e maior assistência por parte dos órgãos gestores, o que, segundo Putnam (2002), contribui para a estabilidade do governo democrático, com efeitos internos sobre os indivíduos e externos sobre a sociedade. Sendo, portanto, um importante instrumento também na redução de restrições sofridas por mulheres no ambiente rural.

Tabela 15 - Participação dos agricultores familiares (\%), por sexo do responsável do estabelecimento, em entidades associativas no estado do Pará

\begin{tabular}{cccc}
\hline Entidade associativa & Homens (\%) & Mulheres (\%) & Média Geral (\%) \\
\hline Entidade de classe/sindicato & 30,18 & 33,25 & 30,83 \\
Associação/movimento de produtores & 10,31 & 9,56 & 10,15 \\
Associação de moradores & 4,61 & 6,35 & 4,98 \\
Cooperativa & 1,91 & 1,55 & 1,83 \\
\hline
\end{tabular}

Fonte: Censo Agropecuário 2017.

Na agricultura familiar o acesso aos serviços de assistência técnica pelos agricultores (Tabela 16) é limitado, sendo que $94,89 \%$ dos homens e $95,87 \%$ das mulheres não recebem 
nenhum tipo assistência técnica em seus estabelecimentos rurais. $O$ acesso a esses serviços é fundamental, uma vez que, a insuficiência e, em muitos casos, a ausência da assistência técnica configura-se como um importante "gargalo" para agricultura familiar paraense.

Considerando todas as organizações provedoras de serviços de assistência técnica no meio rural (públicas e privadas), o percentual de famílias que recebem assistência é muito baixo, inferior a 6\%. Segundo Nobre (2012), essa realidade é global e a partir dos dados de países em desenvolvimento foi constatado que os agricultores e agricultoras têm pouco acesso aos serviços de assistência técnica e extensão rural e, dentro desse contexto, as mulheres ainda estão em pior situação.

Tabela 16 - Acesso aos serviços de assistência técnica pelos agricultores familiares (\%), por sexo do responsável do estabelecimento, estado do Pará

\begin{tabular}{cccc}
\hline Acesso aos serviços de assistência técnica & Homens (\%) & Mulheres (\%) & Total (\%) \\
\hline Não recebe & 94,89 & 95,87 & 95,1 \\
Recebe & 5,11 & 4,13 & 4,90 \\
Entidades governamentais & 3,07 & 2,82 & 3,02 \\
Própria ou do próprio produtor & 0,86 & 0,49 & 0,78 \\
Cooperativas, empresas integradoras e consultorias & 0,73 & 0,49 & 0,68 \\
Outra* & 0,45 & 0,33 & 0,42 \\
\hline Total & 100,00 & 100,00 & 100,00 \\
\hline
\end{tabular}

Fonte: Censo Agropecuário, 2017.

Nesse contexto, também é indispensável a capacitação dos agricultores e ampliação do acesso à informação. De forma geral, a principal fonte de informações técnicas destes produtores ocorre por meio da televisão e rádio. A Tabela 17 ilustra essa realidade apontando que, dentro da porcentagem de homens agricultores, 35,66\% obtém informações por meio da televisão e $24,43 \%$, por meio do rádio. Na perspectiva das mulheres agricultoras, $34,77 \%$ se informa por meio da televisão e $23,26 \%$, por meio de rádio. A falta de acesso às informações também contribui para a ampliação das lacunas de gênero, influenciando o grau de empoderamento das mulheres. 
Tabela 17 - Forma de obtenção de informações técnicas recebidas pelos agricultores familiares (\%), por sexo do responsável do estabelecimento, estado do Pará

\begin{tabular}{cccc}
\hline Formas de acesso às informações técnicas & Homens (\%) & Mulheres (\%) & Total (\%) \\
\hline Televisão & 35,66 & 34,77 & 35,48 \\
Rádio & 24,43 & 23,26 & 24,18 \\
Internet & 3,05 & 2,75 & 2,99 \\
Revistas & 1,28 & 1,22 & 1,27 \\
Jornais & 2,03 & 1,68 & 1,96 \\
Reuniões técnicas/Seminários & 5,12 & 4,90 & 5,07 \\
Outra forma & 26,11 & 25,71 & 26,03 \\
Não obtém informações técnicas & 38,71 & 40,92 & 39,18 \\
\hline
\end{tabular}

Fonte: Censo Agropecuário, 2017.

Em relação ao acesso às políticas de crédito pelas agricultoras familiares, por meio do Programa Nacional de Fortalecimento da Agricultura Familiar - Pronaf, constatou-se que, em 2019, as mulheres representaram um percentual de apenas 20,14\% do total de beneficiários. De forma estratificada por setor, do valor total de $\mathrm{R} \$ 72.334 .298,42$ destinados às agricultoras, $73,56 \%$ foram direcionados para a pecuária e $26,44 \%$ para investimentos no setor agrícola (Tabela 18).

Entre os fatores intrínsecos da dificuldade de acesso ao crédito pela agricultura familiar, para as mulheres somam-se também fatores críticos moldados pelas relações de gênero que contribuem para essa pequena participação de mulheres como tomadoras de crédito. Segundo Siliprandi (2012), em uma conjuntura de relações desequilibradas de poder, alguns fatores dificultam o acesso aos benefícios sociais e às políticas de apoio à agricultura pelas agricultoras, como a precariedade de informações, a falta assistência técnica, restrições de uso e acesso à terra e aos instrumentos de produção, falta de remuneração e de identificação da mulher como produtora rural, juntamente com dificuldades de obtenção registro profissional, entre outros. Em contrapartida, dentro desse cenário, esses fatores quase sempre são apropriados apenas por homens, o que amplia as disparidades presentes nas relações de gênero.

É importante destacar que, nesse contexto, o crédito rural se configura como um importante fator de amplificação do acesso ao recurso, além de, segundo Souza, Santos e Rebello (2018), ser um instrumento de desenvolvimento e contribuir para a eficiência produtiva e potencialização, resultando em maiores níveis de rentabilidade e sustentabilidade, o que amplia a segurança alimentar e a qualidade de vida das populações rurais. 
Tabela 18 - Valor de crédito e percentual de Homens e mulheres que tiveram acesso ao Programa Nacional de Fortalecimento da Agricultura Familiar - Pronaf, por setor e por sexo dos responsáveis - Pará 2019

\begin{tabular}{ccccc}
\hline Acesso a crédito & Homem & Homem (\%) & Mulher & Mulher (\%) \\
\hline Agrícola & $\mathrm{R} \$ 62.492 .678,38$ & 21,79 & $\mathrm{R} \$ 19.127 .874,33$ & 26,44 \\
Pecuária & $\mathrm{R} \$ 224.293 .932,68$ & 78,21 & $\mathrm{R} \$ 53.206 .424,09$ & 73,56 \\
\hline Total & $\mathrm{R} \$ 286.786 .611,06$ & 100,00 & $\mathrm{R} \$ 72.334 .298,42$ & 100,00 \\
\cline { 2 - 5 } & \multicolumn{4}{c}{ Percentual das operações de crédito rural } \\
\cline { 2 - 5 } & liberado para homens & $\begin{array}{c}\text { Percentual das operações de crédito rural } \\
\text { liberado para Mulheres }\end{array}$ \\
\hline Total (\%) & 79,86 & \multicolumn{2}{c}{20,14} \\
\hline
\end{tabular}

Fonte: Banco Central do Brasil, 2019.

Esses resultados também dialogam com outros importantes Objetivos de Desenvolvimento Sustentável (ODS), como: (objetivo 1) acabar com a pobreza em todas suas formas e em todos os lugares; (objetivo 2) acabar com a fome, alcançar a segurança alimentar e melhoria da nutrição e promover a agricultura sustentável; (objetivo 3) assegurar a vida saudável e promover bem estar para todos, em todas as idades; (objetivo 8) promover o crescimento econômico sustentado, incluso e sustentável, emprego pleno e produtivo e trabalho decente para todos; e (objetivo 10) reduzir a desigualdade dentro dos países e entre eles; entre outros objetivos que não são específicos para mulheres, mas com efeito direto a elas e que denotam a importância das mulheres como agentes protagonistas do desenvolvimento.

\section{Conclusão}

Os resultados comprovam uma grande desigualdade presente na agricultura familiar paraense, o que merece uma particular atenção, principalmente quando se pensa na perspectiva das mulheres agricultoras.

Entre as variáveis que tiveram maior disparidade estão o número estabelecimentos agropecuários gerenciados pelas mulheres, o tamanho das propriedades, a posse e uso da terra, o baixo acesso ao crédito e assistência técnica.

O perfil das agricultoras, em sua maioria, compreende mulheres na faixa etária de 35 a 45 anos (22,51\%), de cor parda (69,49\%) e com baixo nível de escolaridade. Sua mão de obra está alocada, principalmente, em atividades produtivas que compreendem um maior percentual de lavouras temporárias (38,67\%). 
Entre as principais limitações estão o alto número de mulheres que não utilizam de práticas de conservação e manejo devido à falta de informação de qualidade e assistência técnica, visto que se observou, mesmo que timidamente, uma maior predisposição por parte das mulheres agricultoras na adoção de práticas sustentáveis de produção.

Esses resultados apontam para uma grande necessidade de capacitação destas agricultoras e identificação delas como atores estratégicos na agricultura paraense. É necessário garantir seus direitos como cidadãs e investir em políticas que visem emancipálas, e que sejam capazes de mitigar não somente as lacunas de gênero, mas as empoderar em todos os âmbitos.

É preciso haver um esforço por parte dos órgãos governamentais para realizar mudanças na forma como são realizados os levantamentos de dados, pois, atualmente, estes não captam com maior precisão o papel da mulher na agricultura, tendo em vista ainda haver possibilidade de uma subnotificação das contribuições em algumas das variáveis aqui analisadas, em função das particularidades das relações às quais estão submetidas dentro dos sistemas de produção.

A garantia das liberdades individuais dessas mulheres por meio de políticas e ações voltadas para a redução da desigualdade no campo e a valorização do seu capital humano, tendo a justiça social como um de seus pilares, deve ser um esforço de governos e de toda a sociedade, visando o desenvolvimento sustentável.

\section{Agradecimentos}

Os autores agradecem o apoio financeiro da Coordenação de Aperfeiçoamento de Pessoal de Nível Superior (CAPES) - Código Financeiro 001.

\section{Referências}

ALMEIDA, R. Amazônia, Pará e o mundo das águas do Baixo Tocantins. Estudos Avançados, v. 24, n. 68, p. 291-298, 2010.

BANCO MUNDIAL. Relatório Anual de 2019: erradicar a pobreza, investir em oportunidades. Washington D, C.:World Bank, 2019. Disponível em: http://documents.worldbank.org/curated/pt/921181570464852907/TheWorld-Bank-Annual-Report-2019-Ending-Poverty-Investing-in-Opportunity. Acesso em: 26 ago. 2019.

BANCO MUNDIAL. World Development Report 2012: gender equality and development. Washington, D.C.: World Bank, 2011. Disponível em: https://openknowledge.worldbank.org/handle/10986/4391. Acesso em: 22 jun. 2019. 
BARROS, S. C. V.; MOURÃO. L. Panorama da participação feminina na educação superior, no mercado de trabalho e na sociedade. Psicologia \& Sociedade, v. 30, p. 1-11, out. 2018.

BOESSIO, A. T.; DOULA, S. M. Jovens rurais e influências institucionais para a permanência no campo: um estudo de caso em uma cooperativa agropecuária do Triângulo Mineiro. Interações, v. 17, n. 3, p. 370-383, jul./set. 2016.

BRASIER, K. J.; SACHS, C. E.; KIERNAN, N. E.;TRAUGER, A.; BARBERCHECK, M. E. Capturing the multiple and shifting identities of farm women in the northeastern United States. Rural Sociology, v. 79, n. 3, p. 283-309, 2014.

BRASIL. Lei no 11.326, de 24 de julho de 2006. Estabelece as diretrizes para a formulação da Política Nacional da Agricultura Familiar e Empreendimentos Familiares Rurais. Diário Oficial da União: seção 1, Brasília, DF, p.1,25 jun. 2006. Disponível em: Disponível em: https:/www2.camara.leg.br/legin/fed/lei/2006/lei-11326-24-julho2006-544830-publicacaooriginal-56358-pl.html. Acesso em: 27 set. 2020.

BRUMER, A. Gênero e agricultura: a situação da mulher na agricultura do Rio Grande do Sul. Estudos Feministas, v. 12, n. 1, p. 205-227, jan./abr. 2004.

BRUMER, A.; ANJOS, G. Gênero e reprodução social na agricultura familiar. Revista Nera, v. 11, n. 12, p. 6-17, jan./jun. 2008.

BUTTO, A.; HORA, K. Políticas públicas do Ministério do Desenvolvimento Agrário para as Mulheres Rurais. In: DALLER, V. L. O.; MOREIRA, E. M. A. Cooperativismo de gênero. Brasília: Mapa/ACS, p.57-68, 2008.

CARVALHO, M. P. O conceito de gênero: uma leitura com base nos trabalhos do GT Sociologia da Educação da ANPEd (1999-2009). Revista Brasileira de Educação, v. 16, n. 46, p. 99-117, jan./abr. 2011.

CONFEDERAÇÃO NACIONAL DE MUNICÍPIOS. Guia para localização dos objetivos de desenvolvimento sustentável nos municípios brasileiros: o que os gestores municipais precisam saber. Brasília: CNM, 2016.132 p.

COROMALDI, M.; PALLANTE, G.; SAVASTANO, S. Adoption of modern varieties, farmers' welfare and crop biodiversity: Evidence from Uganda. Ecological Economics, v. 119, p. 346-358, nov. 2015.

DAL SOGLIO, F.; KUBO, R. R. Desenvolvimento, agricultura e sustentabilidade. Porto Alegre: Editora da UFRGS, 2016. $206 \mathrm{p}$.

DEERE, C. D.; LÉON, M. Diferenças de gênero em relação a bens: a propriedade fundiária na América Latina. Sociologias, v. 5, n. 10, p. 100-153, jul./dez. 2003.

DOSS, C.; Meinzen-Dick, R. Land tenure security for women: A conceptual framework. Land Use Policy, v. 99, n. 1, p.1-12, dez. 2020.

FORTINI, S. M.; BRAGA, M. J.; FREITAS, C. O. Impacto das práticas agrícolas conservacionistas na produtividade da terra e no lucro dos estabelecimentos agropecuários brasileiros. Revista de Economia e Sociologia Rural, v. 58, n. 2. p,1-19, 2020.

FORUM ECONÔMICO MUNDIAL. Global Gender Gap Report 2020. Geneva, Switzerland: World Economic Forum, 2020. Disponível em: https://www.weforum.org/reports/gender-gap-2020-report-100-years-payequality. Acesso em: 29 set. 2020.

FUNDAÇÃO AMAZÔNIA DE AMPARO A ESTUDOS E PESQUISAS. Boletim Agropecuário do Pará 2017. Belém: FAPESPA, 2017. Disponível em: http://www.fapespa.pa.gov.br/upload/Arquivo/anexo/1383. pdf?id=1533567716. Acesso em: 25 set. 2020.

INSTITUTO BRASILEIRO DE GEOGRAFIA E ESTATÍSTICA. Censo Agropecuário 2017. Brasília: IBGE, 2017. Disponível em: https://censos.ibge.gov.br/agro/2017/. Acesso em: 23 mar. 2020. 
INSTITUTO BRASILEIRO DE GEOGRAFIA E ESTATÍSTICA. Desigualdades sociais por cor ou raça no Brasil. Brasília: IBGE, 2019. Disponível em: https://biblioteca.ibge.gov.br/visualizacao/livros/liv101681_informativo. pdf. Acesso em: 12 set. 2020.

INSTITUTO BRASILEIRO DE GEOGRAFIA E ESTATÍSTICA. Estatísticas de gênero: Indicadores sociais das mulheres no Brasil. Brasília: IBGE, 2018. Disponível em: https://biblioteca.ibge.gov.br/visualizacao/livros/ liv101551_informativo>.pdf. Acesso em: 12 de fev. de 2019.

INSTITUTO DE PESQUISA ECONÔMICA APLICADA. Agricultura familiar, assistência técnica e extensão rural e a política nacional de Ater. Brasília: Rio de Janeiro: Ipea, 2017. Disponível em: http://repositorio.ipea.gov.br/ handle/11058/8114. Acesso em: 15 set. 2020.

INSTITUTO NACIONAL DE ESTUDOS E PESQUISAS EDUCACIONAIS ANÍSIO TEIXEIRA. Mulheres são maioria na Educação Superior brasileira. Brasília: INEP, 2018. Disponível em: http://portal.inep.gov.br/artigo/-/asset_ publisher/B4AQV9zFY7Bv/content/mulheres-sao-maioria-na-educacao-superior-brasileira/21206. Acesso em: 12 set. 2020.

MASAMHA, B.; UZOKWE, V. N. E.; THEBE, V. Women's empowerment in traditional food value chains at the micro level: Evidence from cassava smallholder farming in Tanzania. Agroecology and Sustainable Food Systems, v. 42, n. 1, p. 28-47, jun. 2018.

MULLER, M. M. L.; GUIMARÃES, M. F.; DESJARDINS, T.; MARTINS, P. F. S. Degradação de pastagens na Região Amazônica: propriedades físicas do solo e crescimento de raízes. Pesquisa Agropecuária Brasileira, v. 36, n. 11, p. 1409-1418, nov. 2001.

NATH, T. D.; ATHINUWAT, D. Key factors of women empowerment in organic farming. GeoJournal, v. 85, n. 6, p. 1-20, mai.2020.

NOBRE, M. Censo Agropecuário 2006 - Brasil: uma análise de gênero. In: BUTTO, A.; DANTAS, I.; HORA, K. As mulheres nas estatísticas agropecuárias: experiências em países do Sul. 1. ed. Brasília: Ministério do Desenvolvimento Agrário, 2012. p. 41-118.

ORGANIZAÇÃO DAS NAÇÕES UNIDAS PARA ALIMENTAÇÃO E AGRICULTURA. Las mujeres en la agricultura: Cerrar la brecha de género en aras del desarrollo. Rome: FAO, 2011. Disponível em: http://www.fao.org/3/ i2050s/i2050s00.htm. Acesso em: 21 mar. 2019.

ORGANIZAÇÃO DAS NAÇÕES UNIDAS PARA ALIMENTAÇÃO E AGRICULTURA. Manual sobre género en agricultura. Rome: FAO, 2012. Disponível em: http://www.fao.org/3/a-aj288s.pdf. Acesso em: 04 set. 2019.

ORGANIZAÇÃO DAS NAÇÕES UNIDAS. Transformar nuestro mundo: la Agenda 2030 para el Desarrollo Sostenible (Resolución 70/1). New York: ONU, 2015. Disponível em: https://unctad.org/meetings/es/ SessionalDocuments/ares70d1_es.pdf. Acesso em 3 nov. 2019.

PAES, R. S.; ZAPPES, C. A. Agricultura familiar no norte do estado do Rio de Janeiro: identificação de manejo tradicional. Sociedade \& Natureza, v. 28, n. 3, p. 385-395, set./dez.2016.

PROGRAMA DAS NAÇÕES UNIDAS PARA O DESENVOLVIMENTO. Desenvolvimento Humano para Além das Médias: 2017. Brasília: PNUD-IPEA-FJP, 2017. 127 p.

PROGRAMA DAS NAÇÕES UNIDAS PARA O DESENVOLVIMENTO. Human Development Report 2016: Human Development for Everyone. Washington DC, USA: UNDP, 2016. Disponívelem: https://www.br.undp.org/ content/brazil/pt/home/idh0/relatorios-de-desenvolvimento-humano/rdhs-globais.html\#2016. Acesso em: 15 de set de 2020.

PETRY, J. F.; SEBASTIÃO, S. A.; MARTINS, E. G.; BARROS, P. B. A. Inovação e difusão de tecnologia na agricultura de várzea na Amazônia. Revista de Administração Contemporânea, v. 23, n. 5, p. 619-635, se.t/out. 2019. 
PUTNAM, R.D. Comunidade e democracia: a experiência da Itália moderna. 3. ed. Rio de Janeiro: FGV, 2002. p.260.

SANTOS, A. M.; MITJA, D. Agricultura familiar e desenvolvimento local: os desafios para a sustentabilidade econômico-ecológica na comunidade de Palmares II, Parauapebas, PA. Interações, v. 13, n. 1, p. 39-48, jan./ jun. 2012.

SANTOS, M. A. S.; SILVA, M. Y. C. Agricultura urbana e periurbana na Região Metropolitana de Belém: um estudo exploratório com produtores de hortaliças no município de Marituba. Movendo Ideias, v. 12, n. 1, p. 85-93, 2007.

SILIPRANDI, E. Pobreza rural, agricultura e segurança alimentar: os muitos caminhos do empoderamento das mulheres. Revista do Observatório Brasil da Igualdade de Gênero. Edição especial: Desenvolvimento Sustentável e Igualdade de Gênero, p. 22-28, 2012.

SILVA, J. S.; MARJOTTA-MAISTRO, M. C.; SANTOS, M. A. S.; BARBOSA, A. S. A; BEZERRA, A. S. Socioeconomic and environmental characterization of urban backyards in the Marituba municipality, Belém Metropolitan Region, Pará State, Brazilian Amazon. International Journal of Development Research, v. 9, n. 8, p. 2949529502, 2019.

SOUZA, C. C. M.; SANTOS, M. A. S.; REBELLO, F. K. Espacialização e concentração das aplicações de crédito rural no Brasil entre 2007 e 2017. Agrarian Academy, v. 5, n. 10, p. 82-92, 2018.

SPANEVELLO, R. M.; MATTE, A.; BOSCARDIN, M. Crédito rural na perspectiva das mulheres trabalhadoras rurais da agricultura familiar: uma análise do Programa Nacional de Fortalecimento da Agricultura Familiar (PRONAF). Revista Latinoamericana, v. 15, n. 44, p. 393-414. 2016.

SUNDERLAND, T.; RAMADHANI, A.;BABIGUMIRA, R.; AGELSEN, A.; ICKOWITZ, A.;PAUMGARTEN, F.; REYES-GARCIA, V.; SHIVELY, G. Challenging perceptions about men, women, and forest product use: A global comparative study. World Development, v. 64, n. 1, p. 56-66, 2014.

TARA SATYAVATHI, C.; BHARADWAJ, C.; BRAHMANAND, P. Role of Farm Women in Agriculture, Lessons Learned. Gender, Technology and Development, v. 14, n. 3, p. 441-449. 2010.

VEIGA, J. E. O Brasil rural ainda não encontrou seu eixo de desenvolvimento. Estudos Avançados, v. 15, n. 43, p.101-119 set./out. 2001.

VIEIRA FILHO, J. E. R. Agricultura e indústria no Brasil: inovação e competitividade. Brasília: Ipea, 2017. 305p. 